\title{
Article
}

\section{The effect of minimalist, maximalist and energy return footwear of equal mass on running economy and substrate utilization}

Sinclair, Jonathan Kenneth, Shore, Hannah and Dillon, Stephanie Available at https://clok.uclan.ac.uk/13506/

Sinclair, Jonathan Kenneth orcid iconORCID: 0000-0002-2231-3732, Shore, Hannah and Dillon, Stephanie orcid iconORCID: 0000-0002-3369-8199 (2016) The effect of minimalist, maximalist and energy return footwear of equal mass on running economy and substrate utilization. Equine and Comparative Exercise Physiology, 12 (1). pp. 49-54. ISSN 1755-2540

It is advisable to refer to the publisher's version if you intend to cite from the work. http://dx.doi.org/10.3920/CEP150029

For more information about UCLan's research in this area go to http://www.uclan.ac.uk/researchgroups/ and search for <name of research Group>.

For information about Research generally at UCLan please go to http://www.uclan.ac.uk/research/

All outputs in CLoK are protected by Intellectual Property Rights law, including Copyright law. Copyright, IPR and Moral Rights for the works on this site are retained by the individual authors and/or other copyright owners. Terms and conditions for use of this material are defined in the policies page. 


\title{
The effect of minimalist, maximalist and energy return footwear of equal mass on running economy and substrate utilisation
}

\author{
J. Sinclair ${ }^{*}{ }^{*}$ H. Shore ${ }^{1}$ and S. Dillon ${ }^{2}$ \\ 1Division of Sport Exercise and Nutritional Sciences, University of Central Lancashire, Fylde Road, PR1 2HE Preston, United Kingdom; \\ ${ }^{2}$ International Institute of Nutritional Science and Food Safety Studies, University of Central Lancashire, Fylde Road, PR1 2HE Preston, United \\ Kingdom; jksinclair@uclan.ac.uk
}

Received: 24 September 2015 / Accepted: 6 January 2016

(c) 2016 Wageningen Academic Publishers

\section{RESEARCH ARTICLE}

\begin{abstract}
The aim of the current study was to explore the effects of minimalist, maximalist and energy return footwear of equal mass on economy and substrate utilisation during steady state running. Ten male runners completed $6 \mathrm{~min}$ steady state runs in minimalist, maximalist and energy return footwear. The mass of the footwear was controlled by adding lead tape to the lighter shoes. Running economy, shoe comfort, rating of perceived exertion and \% contribution of carbohydrate to total calorie expenditure were assessed. Participants also subjectively indicated which shoe condition they preferred for running. Differences in shoe comfort and physiological parameters were examined using paired samples t-tests, whilst shoe preferences were tested using a chi-square test. The results showed firstly that running economy was significantly improved in the energy return $(35.9 \mathrm{ml} \cdot \mathrm{kg} / \mathrm{min})$ compared to minimalist footwear $(37.8 \mathrm{ml} \cdot \mathrm{kg} / \mathrm{min})$. In addition \% carbohydrate was significantly greater in the minimalist (76.4\%) in comparison to energy return footwear (72.9\%). As running economy was improved and carbohydrate utilisation reduced in the energy return in comparison to minimalist footwear, the current investigation shows that these footwear are more economical when shoe mass is controlled.
\end{abstract}

Keywords: running; economy; footwear; performance

\section{Introduction}

Endurance in runners is delineated as the capacity to maintain a defined work output (Jones, 2006). During aerobic exercise, such as running, the majority of the energy is supplied through oxidative phosphorylation via the aerobic re-synthesis of adenosine triphosphate (Jones, 2006). This metabolic process requires the delivery of oxygen and the availability of fuels in the form of both carbohydrates and fats.

Running economy is a reflection of the amount of oxygen which must be consumed in order to maintain a given steady state running velocity (Daniels, 1985). Running economy is considered to be strongly associated with running performance (Cavanagh and Williams, 1982; Di Prampero, 2003; Saunders et al., 2004), serving as a better predictor of performance than indices of maximum aerobic capacity (Hanson et al., 2010). Greater economy is an indication that a runner is operating at a lower percentage of their maximum aerobic capacity for the same work output. It is known that physiological, biomechanical and anthropometric factors can influence running economy (Saunders et al., 2004; Williams and Cavanagh, 1987), although research in this area is still in its infancy. Nonetheless, given its association with performance, increased economy is of significant interest to both runners and researchers alike.

Altering the mechanical characteristics of footwear has been hypothesised as a means by which economy can be improved in runners (Frederick et al., 1986). The findings from some research have supported this claim. Bosco and Rusco (1983) showed that a viscoelastic insert significantly improved running economy compared to running without the insert. Frederick et al. (1986) demonstrated that running 
in a shoe with an inflated cushioning system significantly improved running economy. The findings of Worobets et al. (2014) showed that a soft shoe improved running economy in relation to a control shoe during overground and treadmill running. Sinclair et al. (in press) demonstrated that new energy return footwear with a polyurethane midsole improved running economy and reduced runners reliance on carbohydrate as an energy source in comparison to a conventional running shoe. Conversely, some research has shown that footwear does not influence running economy. Nigg et al. (2003) showed that footwear with different midsole cushioning characteristics as opposed to using hard midsoles did not significantly improve running economy. Sinclair et al. (2014) similarly showed that footwear with different midsole cushioning properties did not significantly improve running economy.

In recent years running barefoot and in minimalist footwear has been the focus of much attention in biomechanical research. Much of the work into the effects of footwear on running economy has focused on the effects of running barefoot and in minimalist footwear (Cheung and Ngai, in press). Advocates of barefoot and minimalist footwear claim that traditional shod running is less economical (Cheung and Ngai, in press; Franz et al., 2012). Squadrone and Gallozi (2009) demonstrated that running in minimalist footwear mediated significant improvements in running economy in comparison to wearing conventional running shoes. Moore et al. (2014) similarly investigated the influence of minimalist and conventional footwear on running economy. Their observations showed that running in minimalist footwear was associated with significant improvements in running economy compared to conventional footwear. Similarly, Hanson et al. (2010) showed that barefoot running was more economical in comparison to shod. However, as shoe mass is known to increase the oxygen cost of running for a given velocity (Frederick et al., 1986); studies of this nature have been scrutinised as minimalist footwear are typically much lighter. Franz et al. (2012) investigated the effects of minimalist footwear on running economy but with additional mass added to the footwear so that the total mass was equitable between conditions. Their findings indicate that when the effects of shoe mass were controlled, the oxygen cost of running was significantly greater when running barefoot.

Even more recently, the footwear industry has changed focus and used the opposite approach to footwear design by introducing maximalist footwear. Maximalist running shoes feature a very large midsole which is designed to provide additional cushioning in comparison to conventional running shoes. Currently, only one published investigation exists regarding the biomechanics of running in maximalist footwear. Sinclair et al. (2015) investigated the influence of minimalist, conventional and maximalist footwear on the loads experienced by the Achilles tendon. Their findings showed that Achilles tendon loads were significantly greater in the conventional and maximalist in relation to the minimalist footwear. No published information currently exists regarding the influence of maximalist footwear on running economy. Indicating that investigation into the effects of these new footwear on running economy in relation to minimalist and energy return footwear is warranted.

The aim of the current study was to explore the effects of minimalist, maximalist and energy return footwear of equal mass on economy and substrate utilisation during steady state running. A study of this nature will provide additional information that will help to understand the mechanisms by which different footwear may influence running economy. This study tests the hypothesis that energy return footwear serve to improve running economy.

\section{Materials and methods}

\section{Participants}

Ten male recreationally trained runners took part in this study. All participants habitually wore conventional footwear for their running activities. The mean characteristics of the participants were: age $23.4 \pm 2.1$ years, height $176.8 \pm 4.9 \mathrm{~cm}$ and body mass $74.6 \pm 5.8 \mathrm{~kg}$. All were free from pathology at the time of data collection and written informed consent was provided in accordance with the declaration of Helsinki. Pilot work undertaken using a force platform, during overground running showed that all participants exhibited a rearfoot strike pattern as they presented with a first peak in their vertical ground reaction force curve (Cavanagh and Lafortune, 1980). The procedure utilised for this investigation was approved by the University of Central Lancashire, Science, Technology, Engineering and Mathematics, ethical committee.

\section{Procedure}

Participants each ran at $13 \mathrm{~km} / \mathrm{h}$ treadmill (H/P/Cosmos, Nussdorf-Traunstein, Germany) with the incline maintained at a $0 \%$ (Sinclair et al., in press). The velocity of the treadmill belt was validated prior to data collection in accordance with Sinclair et al. (2014). In agreement with the procedure documented by Hanson et al. (2010), participants were required to undertake a $3 \mathrm{~min}$ habituation period in all footwear conditions, during which they ran at the required velocity prior to the commencement of data collection.

Respiratory gases were collected throughout testing using a gas analysis system (MetaLyser 3B system, Cortex Biophysic, Leipzig, Germany). In order to eliminate the potential variation in oxygen consumption $\left(\mathrm{VO}_{2}\right)$ due to circadian rhythmicity, each data collection session was conducted at the same time of day. Participants were required to maintain 
their habitual dietary intake in the $48 \mathrm{~h}$ prior to testing and attend the laboratory a minimum of $4 \mathrm{~h}$ postprandial. The order of wearing each footwear was randomised to prevent any order effects (Frederick et al., 1986). Data collection initially began with the collection of baseline data, this involved 10 mins of quiet standing.

Following this, participants completed 6 min steady state runs in agreement with Nigg et al. (2003). Participants completed their runs in all shoe conditions within the same testing session with rest in between. The subsequent testing condition was not started until the $\mathrm{VO}_{2}$ returned to within $0.025 \mathrm{l} / \mathrm{min}$ of the baseline value. The test-retest reliability of the metalyzer for this protocol has been investigated previously and shown to be very good $\left(R^{2}=0.95\right)$ (Sinclair et al., 2014).

\section{Data processing}

From the baseline data the second 5 min were averaged to create a resting $\mathrm{VO}_{2}$ value. This value was then subtracted from the mean $\mathrm{VO}_{2}$ obtained during the running trials to give a net oxygen consumption value $(\mathrm{ml} \cdot \mathrm{kg} / \mathrm{min})$. The amount of carbohydrate and fat utilisation in $\mathrm{g} / \mathrm{min}$ were determined using the mean rates of inspired oxygen $\left(\mathrm{VO}_{2}\right)$ and expired carbon dioxide $\left(\mathrm{VCO}_{2}\right)$ from the running trials according to the following (McArdle et al., 2010) formulas:

Carbohydrate $=4.58 \times \mathrm{VCO}_{2}-3.23 \times \mathrm{VO}_{2}$

Fat $=1.70 \times \mathrm{VO}_{2}-1.69 \times \mathrm{VCO}_{2}$

Once the amounts of carbohydrate and fat utilised during the running trials were obtained the total number of kilocalories could then be calculated by multiplying the data for carbohydrate by 4 and the data for fat by 9 and summing the contribution of the two substrates. Finally, the relative contribution of carbohydrate to total kilocalories (\% carbohydrate) was obtained by dividing the number of kilocalories exclusive to carbohydrate by the total kilocalories.

Participants were also asked to rate their perceived exertion (RPE) using the 6-20 point Borg scale at 2 min intervals (Sinclair et al., in press). After each 6 min run participants were asked to provide their rating of the comfort of each shoe. The comfort measurement procedure consisted of a $150 \mathrm{~mm}$ visual analogue scale with the extreme left side being indicative of 'not comfortable at all' and the extreme right of the scale labelled as 'most comfortable condition imaginable' (Mündermann et al., 2002). Upon conclusion of the data collection, participants were also asked to subjectively indicate which shoe condition that they preferred for running.

\section{Experimental footwear}

The running shoes used during the current investigation consisted of minimalist (Vibram five-fingers, EL-X; Vibram, Albizzate, Italy), maximalist (Hoka One-One, Goleta, CA, USA) and energy return footwear (Adidas energy boost; Adidas, Herzogenaurach, Germany), (shoe size 8-10 UK men's). As the energy return and minimalist footwear were lighter than the maximalist shoes lead tape was applied until they reached the same mass as maximalist condition (Figure 1). The lead tape was positioned such that the additional mass did not affect the 3-D static balance of the footwear (Sinclair et al., 2014, 2015).

\section{Statistical analysis}

Means, standard deviations and 95\% confidence intervals were calculated for each outcome measure for each footwear condition. Differences in between footwear were examined using one-way repeated measures ANOVAs, with significance accepted at the $P \leq 0.05$ level (Sinclair et al., 2013a). Effect sizes were calculated using partial eta ${ }^{2}$ $\left(\mathrm{p} \eta^{2}\right)$. Post-hoc pairwise comparisons were conducted on all significant main effects. In addition to this percentage differences were also calculated for all statistically significant effects. Finally, a chi-squared $\left(x^{2}\right)$ test was utilised to test

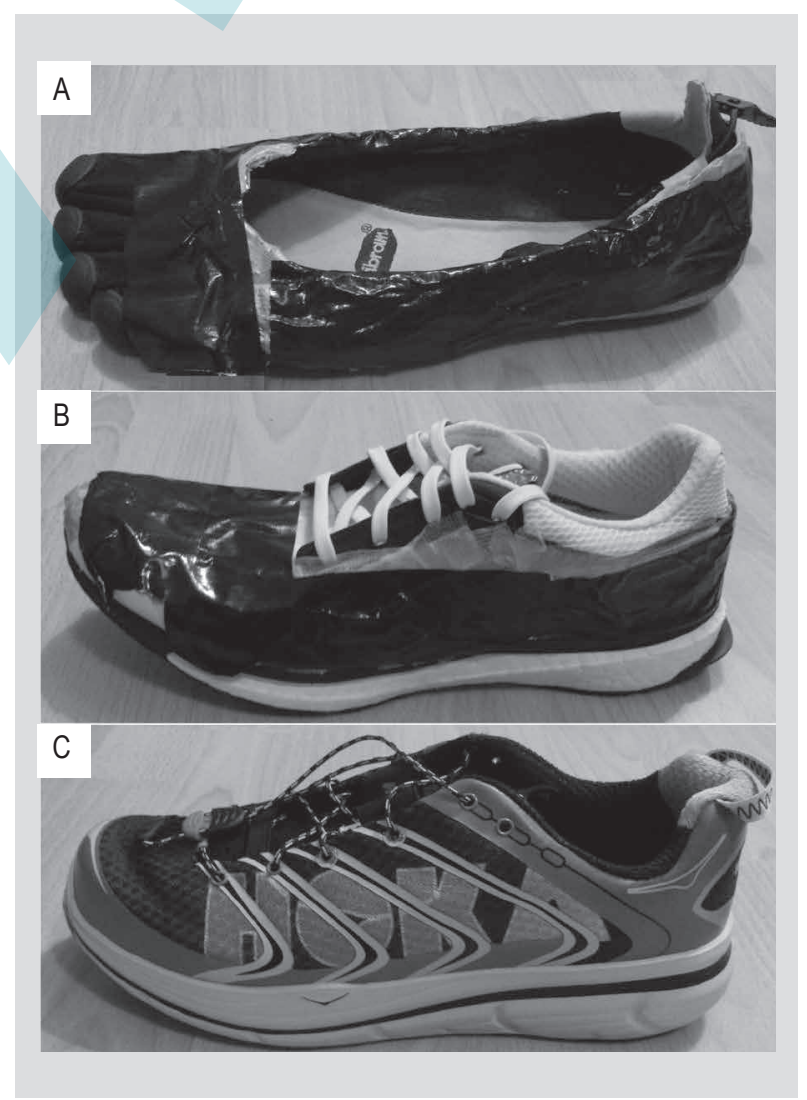

Figure 1. Experimental footwear with additional mass $(A=$ minimalist, $B=$ energy return, and $C=$ maximalist). 
the assumption that an equal number of participants would subjectively favour each of the footwear conditions. All statistical actions were conducted using SPSS v22.0 (SPSS Inc., Chicago, IL, USA).

\section{Results}

\section{$\mathrm{VO}_{2}$ and $\%$ carbohydrate}

A main effect $\left(P \leq 0.05, \mathrm{p}^{2}=0.43\right)$ was shown for net $\mathrm{VO}_{2}$ (Table 1). Post-hoc pairwise comparisons indicate that net $\mathrm{VO}_{2}$ was significantly larger in the minimalist footwear compared to the energy return footwear. In addition, a main effect $\left(P \leq 0.05, \mathrm{p}^{2}=0.32\right)$ was also found for $\%$ carbohydrate utilisation (Table 1). Post-hoc pairwise comparisons showed that \% carbohydrate utilisation was significantly larger in the minimalist in comparison to the energy return footwear.

\section{Rating of perceived exertion}

No significant $(P>0.05)$ difference in RPE was shown (Table 1).

\section{Shoe comfort and preference}

A main effect $\left(P \leq 0.05, \mathrm{p}^{2}=0.30\right)$ was observed for shoe comfort (Table 1). Post-hoc pairwise comparisons showed that the energy return footwear were rated as being significantly more comfortable than the minimalist footwear. In addition, the Chi-squared analysis showed that there was no significant difference in footwear preference $\left(X_{(2)}^{2}=3.80, P>0.05\right)$, with 5 preferring the energy return footwear, 3 preferring the maximalist and 2 preferring the minimalist footwear.

\section{Discussion}

The aim of this study was to examine the effects of minimalist, maximalist and energy return footwear of equal mass on running economy and substrate usage during steady state treadmill running. This investigation represents the first comparative study into the effects these footwear on the running economy. A study of this nature may give important information to help to understand the mechanisms by which different footwear may influence running economy

Importantly, the current investigation showed that the energy return footwear was associated with significantly improved running economy in comparison to the minimalist and maximalist conditions. This finding supports our hypothesis and concurs specifically with the observations of Sinclair et al. (in press) who found that energy return footwear significantly improved running economy. This observation does however disagree with the findings of Squadrone and Gallozi (2009) and Moore et al. (2014) who each showed that minimalist footwear was able to improve running economy. It is proposed that this observation relates to the different shoe masses used by Squadrone and Gallozi (2009) and Moore et al. (2014) which is in contrast to the current investigation and those of Sinclair et al. (in press) in which the effects of shoe mass were controlled. This suggests that the findings from previous analyses in which barefoot/minimalist footwear were shown to improve running economy may have been due at least in part to the reduced mass of the footwear.

The causes of this improvement in running economy shown in the energy return footwear are impossible to extrapolate with complete accuracy. Sinclair et al. (in press) speculated that improved running economy in the energy return footwear was mediated by the increase in returned energy from the shoe midsole. Typically minimalist footwear causes habitual rearfoot striker runners to alter their stride characteristics and adopt a mid/forefoot strike pattern (Sinclair et al., 2013b,c). Gruber et al. (2013) proposed that running using a non-habitual strike pattern may produce higher indices of oxygen consumption. It is hypothesised, therefore, that this observation relates to deviations from runners non-optimal stride length/frequency which led to an increase in the amount of oxygen consumption required to complete the same running velocity. Importantly the

Table 1. Mean, standard deviation and $95 \%$ confidence intervals of physiological and shoe comfort parameters for each footwear condition. ${ }^{1}$

\begin{tabular}{|c|c|c|c|c|c|c|c|c|c|}
\hline & \multicolumn{3}{|c|}{ Energy return } & \multicolumn{3}{|c|}{ Minimalist } & \multicolumn{3}{|c|}{ Maximalist } \\
\hline & Mean & SD & $95 \% \mathrm{Cl}$ & Mean & SD & $95 \% \mathrm{Cl}$ & Mean & SD & $95 \% \mathrm{Cl}$ \\
\hline $\mathrm{Net} \mathrm{VO}_{2}(\mathrm{ml} \cdot \mathrm{kg} / \mathrm{min})$ & 35.9 & 3.4 & $33.4-38.4$ & 37.8 & 5.2 & $34.1-41.6$ & 37.8 & 4.9 & $34.4-41.3$ \\
\hline$\%$ Carbohydrate & 72.9 & 8.3 & $66.1-80.9$ & 76.4 & 8.8 & $70.8-84.1$ & 74.1 & 8.6 & $67.9-83.3$ \\
\hline RPE & 10.3 & 0.8 & $9.7-10.9$ & 11.6 & 2.0 & $10.2-13.1$ & 10.4 & 1.2 & $9.5-11.2$ \\
\hline Comfort & 10.0 & 2.4 & 8.3-11.7 & 7.0 & 2.9 & 4.9-9.1 & 9.7 & 1.8 & $8.4-10.9$ \\
\hline
\end{tabular}


current investigation appears to support Franz et al. (2012) who hypothesised that improvements in running economy observed when running barefoot and in minimalist were mediated by reductions in shoe mass rather than biomechanical changes. Furthermore, the findings of the current study in conjunction with those of Franz et al. (2012) whereby oxygen consumption was greater in minimalist footwear indicate that running biomechanics associated with minimalist footwear appear to be less economical.

An additional important observation is that carbohydrate utilisation was significantly greater in the minimalist footwear in comparison to the energy return condition. This finding also concurs with the previous observations of Sinclair et al. (in press) who indicated that running in energy return footwear reduced the bodies' reliance on carbohydrate metabolism. This finding may also be an important one from a performance perspective, as running places high demands on the bodies carbohydrate stores (Jones, 2006). Reductions in the contribution of carbohydrate to energy expenditure may be important in long distance events whereby the reduced reliance on carbohydrate may delay the onset of glycogen depletion which has been demonstrated as a limiting factor in aerobic performance (Rapoport et al., 2010). However, taking into account the RPE values observed in all footwear conditions, the current investigation examined runners at relatively low intensities. As such the limiting effects of an enhanced rate of carbohydrate utilisation may not be relevant. Therefore an avenue for further research would be to examine the effects of different footwear at more realistic race intensities; this would allow further extrapolation of the findings.

A further important finding is that the energy return footwear were subjectively rated as being significantly more comfortable than the minimalist condition. This concurs with the findings of Sinclair et al. (in press) who also showed that energy return footwear were rated as being more comfortable than conventional running shoes. This observation in conjunction with the metabolic data concurs with the findings of Luo et al. (2009) who showed that running economy was greatest in footwear rated as being the most comfortable. Therefore, the improved comfort shown in the energy return footwear may give additional insight into the differences in running economy shown between energy return and minimalist shoes. It should be noted that the additional mass that was added to the minimalist footwear in particular may have affected the participants' perception of comfort in this condition. The lead tape positioned around the shoe to provide additional mass most likely served to increase the stiffness of the shoe outsole, as such the comfort measures obtained should be interpreted with some caution.

In conclusion, whilst the effects of minimalist and energy return footwear have been investigated previously there has yet to be an examination of running economy and substrate utilisation when running in minimalist, maximalist and energy return footwear. The current investigation therefore provides new information regarding the influence different footwear on running economy and substrate utilisation when the mass of the shoe is controlled. As running economy was improved and carbohydrate utilisation reduced in the energy return in comparison to minimalist footwear, the current investigation shows that these footwear are more economical when shoe mass is controlled.

\section{References}

Bosco, C. and Rusko, H., 1983. The effect of prolonged skeletal muscle stretch-shortening cycle on recoil of elastic energy and on energy expenditure. Acta Physiologica Scandinavica 119: 219-224.

Cavanagh, P.R. and Williams, K.R., 1982. The effect of stride length variation on oxygen uptake during distance running. Medicine and Science in Sports and Exercise 14: 30-35.

Cavanagh, P.R. and Lafortune, M.A., 1980. Ground reaction forces in distance running. Journal of Biomechanics 13: 397-406.

Cheung, R.T. and Ngai, S.P., in press. Effects of footwear on running economy in distance runners: a meta-analytical review. Journal of Science and Medicine in Sport. doi: http://dx.doi.org/10.1016/j. jsams.2015.03.002.

Daniels, J.T., 1985. A physiologist's view of running economy. Medicine and Science in Sports and Exercise 17: 332-338.

Di Prampero, P.E., 2003. Factors limiting maximal performance in humans. European Journal of Applied Physiology 90: 420-429.

Franz, J.R., Wierzbinski, C.M. and Kram, R., 2012. Metabolic cost of running barefoot versus shod: is lighter better? Medicine and Science in Sports and Exercise 44: 1519-1525.

Frederick, E.C., Howley E.T. and Powers S.K., 1986. Lower oxygen demands of running in soft-soled shoes. Research Quarterly for Exercise and Sport 57: 174-177.

Gruber, A.H., Umberger, B.R., Braun, B. and Hamill, J., 2013. Economy and rate of carbohydrate oxidation during running with rearfoot and forefoot strike patterns. Journal of Applied Physiology 115: 194-201.

Hanson, N.J., Berg, K., Deka, P., Meendering, J.R. and Ryan, C., 2010. Oxygen cost of running barefoot vs. running shod. International Journal of Sports Medicine 32: 401-406.

Jones, A., 2006. The physiology of the world record holder for the women's marathon. International Journal of Sports Science and Coaching 1: 101-116.

Luo, G., Stergiou, P., Worobets, J., Nigg, B. and Stefanyshyn, D., 2009. Improved footwear comfort reduces oxygen consumption during running. Footwear Science 1: 25-29.

McArdle, W.D., Katch, F.I. and Katch, V.L., 2010. Exercise physiology: nutrition, energy, and human performance. Lippincott Williams and Wilkins, Philadelphia, PA, USA.

Moore, I.S., Jones, A. and Dixon, S., 2014. The pursuit of improved running performance: can changes in cushioning and somatosensory feedback influence running economy and injury risk? Footwear Science 6: 1-11. 
Mündermann, A., Nigg, B.M., Stefanyshyn, D.J. and Humble, R.N., 2002. Development of a reliable method to assess footwear comfort during running. Gait and Posture 16: 38-45.

Nigg, B.M., Stefanyshyn, D., Cole, G., Stergiou, P. and Miller, J., 2003. The effect of material characteristics of shoe soles on muscle activation and energy aspects during running. Journal of Biomechanics 36: 569-575.

Rapoport, B.I., 2010. Metabolic factors limiting performance in marathon runners. PLoS One Computational Biology 6: 1-13.

Saunders, P.U., Pyne, D.B., Telford, R.D. and Hawley, J.A., 2004. Factors affecting running economy in trained distance runners. Sports Medicine 34: 465-485.

Sinclair, J., Taylor, P.J. and Hobbs, S.J., 2013a. Alpha level adjustments for multiple dependent variable analyses and their applicability - a review. International Journal of Sports Science and Engineering 7: 17-20.

Sinclair, J., Greenhalgh, A., Edmundson, C.J., Brooks, D. and Hobbs, S.J., 2013b. The influence of barefoot and barefoot-inspired footwear on the kinetics and kinematics of running in comparison to conventional running shoes. Footwear Science 5: 45-53.

Sinclair, J., Hobbs, S.J., Currigan, G. and Taylor, P.J., 2013c. A comparison of several barefoot inspired footwear models in relation to barefoot and conventional running footwear. Comparative Exercise Physiology 9: 13-21.
Sinclair, J., Taylor, P.J., Edmundson, C.J., Brooks, D. and Hobbs, S.J. 2014. The influence of footwear kinetic, kinematic and electromyographical parameters on the energy requirements of steady state running. Movement and Sports Sciences 80: 39-49.

Sinclair, J., McGrath, R., Brook, O., Taylor, P.J. and Dillon, S., in press. Influence of footwear designed to boost energy return on running economy in comparison to a conventional running shoe. Journal of Sports Sciences. DOI: http://dx.doi.org/10.1080/02640414.20 15.1088961.

Sinclair, J., Richards, J. and Shore, H., 2015. Effects of minimalist and maximalist footwear on Achilles tendon load in recreational runners. Comparative Exercise Physiology 11: 239-244.

Squadrone, R. and Gallozzi, C., 2009. Biomechanical and physiological comparison of barefoot and two shod conditions inexperienced barefoot runners. Journal of Sports Medicine and Physical Fitness 49: 6-13.

Williams, K.R. and Cavanagh, P.R., 1987. Relationship between distance running mechanics, running economy, and performance. Journal of Applied Physiology 63: 1236-1245.

Worobets, J., Wannop, J.W., Tomaras, E. and Stefanyshyn, D., 2014. Softer and more resilient running shoe cushioning properties enhance running economy. Footwear Science 6: 147-153. 